\title{
In Vitro Antioxidant Activity and Total Phenolic and Flavonoid Contents of Alhydwan (Boerhavia elegana Choisy) Seeds
}

\author{
Al-Farga Ammar ${ }^{1}$, Hui Zhang ${ }^{1, *}$, Azhari Siddeeg ${ }^{1,2}$ \\ ${ }^{1}$ State Key Laboratory of Food Science and Technology \& School of Food Science and Technology, Jiangnan University, Wuxi, China \\ ${ }^{2}$ Department of Food Science and Technology, Faculty of Engineering and Technology, University of Gezira, Wad Medani, Sudan \\ *Corresponding author: zhanghui@jiangnan.edu.cn
}

Received May 03, 2014; Revised May 12, 2014; Accepted May 19, 2014

\begin{abstract}
Alhydwan seeds are widely used by indigenous tribes in the traditional cuisines of South Yemen. The objectives of this study were to determine antioxidant components and antioxidant activities of ethanolic extract of Alhydwan (Boerhavia elegana Choisy) seeds cultivated in Yemen for human consumption (novel plant). The work was done by using several in vitro methods such as 1, 1-diphenyl-2-picrylhydrazyl (DPPH), 2, 2-azino-bis (3ethylbenzthiazoline-6-sulphonic acid) (ABTS), $\beta$-carotene, reducing power and chelating activity. Were also determined total phenolic content by the Folin-Ciocalteu colorimetric and Flavonoid content using catechol. Results showed that B. elegana Choisy seeds had the highest phenol ( $253.9 \pm 0.9 \mathrm{mg} / 1 \mathrm{~g})$, flavonoids (23.68 $\pm 0.6 \mathrm{mg} / 1 \mathrm{~g}$ ), contents; total phenolic content was the most abundant in seeds. B. elegana Choisy seeds exhibited potent DPPH, ABTS, $\beta$-carotene bleaching and metal chelating except reducing power. Effect was also increasing with an increase in B. elegana Choisy concentration. The findings of this study have clearly demonstrated Alhydwan (Boerhavia elegana Choisy) seeds possess high phenolic, flavonoid contents and potential antioxidant activity, and could be used as a viable source of natural antioxidants and might be exploited for functional foods.
\end{abstract}

Keywords: Boerhavia elegana Choisy, antioxidant activity, total phenolic content, total flavonoid compounds, novel plant

Cite This Article: AL-Farga Ammar, Hui Zhang, and Azhari Siddeeg, "In Vitro Antioxidant Activity and Total Phenolic and Flavonoid Contents of Alhydwan (Boerhavia elegana Choisy) Seeds." Journal of Food and Nutrition Research, vol. 2, no. 5 (2014): 215-220. doi: 10.12691/jfnr-2-5-2.

\section{Introduction}

Antioxidants and pro-oxidants are compounds that can accelerate or delay oxidation processes. Nowadays the interest in natural antioxidants has increased considerably because of their beneficial effects of prevention and risk reduction in several diseases [1]. Recently, numerous studies have described antioxidants and compounds with radical scavenging activity to be present in fruits, seeds, vegetables, herbs and cereals extracts [2,3,4]. Antioxidants of natural origin have attracted increasing interest due to they can protect human body from free radicals without producing toxic effects [5]. It is well known that consumption of dietary antioxidants is associated with reduced risk of several diseases in which oxidative stress may play a role, especially chronic diseases such as cardiovascular, cancer and neurodegenerative and inflammatory diseases [6]. Currently, it is an increasing interest in finding natural antioxidants from plant materials to replace synthetic ones [7]. This is due to the fact that natural antioxidant substances are safe since they occur in plant foods and are more desirable than their synthetic counterparts, thus, there is a considerable interest in finding natural antioxidants from plants [8]. Hence, the research on antioxidants has become an important scientific topic in food, pharmaceutical and cosmetic fields [9]. Studies have shown that plants contain a variety of substances, which possess antioxidant activity, such as vitamin C, phenolics, carotenoids and tannins [8]. Phenolic compounds are considered from natural antioxidants, and are biologically active substances [10]. Common bean (Phaseolus vulgaris L.) is a traditional food in human diet, rich in proteins, minerals, complex carbohydrates and vitamins, and low in fat. It is well known that the consumption of the common bean is one of the most widespread practices around the world, accounting for almost half of the consumed legume grains, especially in the less developed countries [11]. Also it's grown and consumed in various regions of the world, It is becoming increasingly popular because of its health benefits, and providing an inexpensive source of protein in the diet [12].

Boerhavia elegana Choisy seeds (common name: alhydwan) is an edible herbaceous member of the Nyctaginaceae family and is commonly available in South Yemen [13]. It is widely used by indigenous tribes in the traditional cuisines of South Yemen, which is one of a staple ingredient in the manufacture of porridge, it is eaten 
as supplement in the mixtures of bread and cakes which is characterized by good flavor, Furthermore, and it is one of the ingredients in the manufacture of desserts and savory products. While some species from genus Boerhavia have been widely used in the traditional system of medicine in many country [14]. Previous study have reported substantial amounts of total phenolic and flavonoid contents and antioxidant activity on species of Boerhavia diffusa from the same genus $[15,16]$. However, to our knowledge, no research has been done up to now or any information available in the literature on species (Boerhavia elegana Choisy) for antioxidant activity and total content of phenolic and flavonoid.

The objectives of this study therefore, were to (i) examine the antioxidant properties of B. elegana Choisy seeds from Yemen; (ii) determine the phenolic and flavonoid contents; and (iii) provide evidence for of alhydwan seeds as a good quality novel plant.

\section{Materials and methods}

\subsection{Materials and Reagents}

Dried alhydwan seeds were brought from a farmland in Hadramout city, Yemen, in December, 2013, and transferred to the Department of Food Science and Technology, Faculty of Engineering and Technology, Jiangnan University, Wuxi City, People's Republic of China. Methanol, chloroform, Ethanol, sodium nitrite, $\mathrm{AlCl}_{3}, \mathrm{FeSO}_{4}, \mathrm{FeCl}_{2}, \mathrm{FeCl}_{3}, \mathrm{NaOH}, \mathrm{Na}_{2} \mathrm{CO}_{3}$, potassium persulphate, sodium carbonate, perchloric acid, and $\mathrm{HCl}$. Were purchased from Sinopharm Chemical Reagent Co., Ltd. (Shanghai, China). Chlorogenic acid, b-Carotene, quercetin, ABTS solution, butylatedhydroxytoluene (BHT), linoleic acid, Tween 20, 2,2-diphenyl-1picrylhydrazyl (DPPH), ascorbic acid, acetate buffer, ferrozine, EDTA, gallic acid, and Folin-Ciocalteu reagent, were purchased from Sigma-Aldrich (St. Louis, MO).All chemicals and reagents in the investigation were of analytical grade.

\subsection{Samples Preparation and Extraction}

The dry alhydwan seeds were milled into powder to pass through 100-mesh sieve, sealed in polyethylene bags and stored in a refrigerator at $4^{\circ} \mathrm{C}$ until use. To obtain an extract, $50 \mathrm{~g}$ of sample was mixed with $150 \mathrm{~mL}$ of $95 \%$ ethanol in a blender for $1 \mathrm{~min}$ and shaken in the dark at $25^{\circ} \mathrm{C}$ for $4.5 \mathrm{~h}$. The mixture was then centrifuged for 20 min at $4^{\circ} \mathrm{C}$ and the supernatant filtered. The extract was evaporated to dryness using a rotary evaporator (IKA, RV10-German). The dry extract was drained under a nitrogen stream and was then stored in a refrigerator at $4^{\circ} \mathrm{C}$ till analysis.

\subsection{Determination of Total Phenolic and Flavonoid Contents}

Total phenolic content (TPC) was analyzed by the Folin-Ciocalteu colorimetric method using gallic acid as standard and expressed as $\mathrm{mg} / \mathrm{g}$ gallic equivalent [17]. Flavonoid content was analyzed using catechol as standard and this was expressed as $\mathrm{mg} / \mathrm{g}$ catechol [18].

\subsection{DPPH Radical Scavenging Activity Assay}

The DPPH Radical scavenging activity was determined according to the technique reported by [19] with a slight modification. Extract concentrations of 1, 2, 4, 8, and 16 mg extract equivalents/ $\mathrm{mL}$ were mixed with $3.5 \mathrm{~mL}$ of DPPH solution and the absorbance was read at $517 \mathrm{~nm}$. The mixtures were incubated for $30 \mathrm{~min}$ at $25^{\circ} \mathrm{C}$. Then, the absorbance was recorded at $517 \mathrm{~nm}$. Ascorbic acid was used as the standard. The DPPH radical scavenging activity was calculated according to the following equation:

$$
\text { DPPH Scavenging activity } \%=\left(\mathrm{A}_{\mathrm{C}}-\mathrm{A}_{\mathrm{s}} / \mathrm{A}_{\mathrm{C}}\right) \times 100
$$

Where:

$A_{c}$ is the absorbance of the control and $A_{s}$ is the absorbance of extract.

\subsection{ABTS Radical Scavenging Assay}

ABTS assay of B. elegana Choisy seeds was based on the method of [20] with slight modifications. Briefly, an aliquot of extract $1,2,4,8$ and $16 \mathrm{mg}$ extract equivalents/mL concentrations were mixed with $900 \mu \mathrm{L}$ of $100 \mathrm{mM}$ Tris-HCl buffer ( $\mathrm{pH} 7.4$ ), $40 \mu \mathrm{L}$ of methanol and $50 \mu \mathrm{L}$ of $0.5 \%$ (w/w) Tween 20 solution, an ABTS radical was generated by mixing $7 \mathrm{mM}$ ABTS and $2.45 \mathrm{mM}$ potassium persulphate via incubation at $23^{\circ} \mathrm{C}$ in the dark for $12 \mathrm{~h}$. Then, $0.1 \mathrm{~mL}$ of the sample solution was mixed with $2.6 \mathrm{~mL}$ of a diluted ABTS radical solution. The absorbance of the solution was recorded at 734nm after incubation at $23^{\circ} \mathrm{C}$ for $6 \mathrm{~min}$. ABTS radical scavenging assay was calculated using the formula: scavenging activity $\%=($ Ac-AS / Ac) $\times 100$, where Ac is the absorbance of the control and As is the absorbance of extract. BHT was used as the standard compound.

\section{6. $\beta$-Carotene Bleaching Test}

Antioxidant activity was determined also using the $\beta$ carotene bleaching test by the method of [21] an amount of one $\mathrm{mL}$ of $\beta$-carotene solution in chloroform (3.34 $\mathrm{mg} / \mathrm{mL}$ ) was pipette into a flask containing $50 \mathrm{mg}$ linoleic acid and $500 \mathrm{mg}$ Tween 20 . The chloroform was removed by rotary evaporation at $40^{\circ} \mathrm{C}$ for $5 \mathrm{~min}$ and $100 \mathrm{~mL}$ of distilled water were slowly added to the solution with vigorous agitation to form an emulsion. A $5 \mathrm{ml}$ aliquot of the emulsion was added to a tube containing $0.2 \mathrm{~mL}$ of the antioxidant solution at $200 \mathrm{mg} / \mathrm{L}$ and the absorbance was measured at $470 \mathrm{~nm}$, immediately, against a blank consisting of the emulsion without $\beta$-carotene. The tubes were then placed in a water bath at $40^{\circ} \mathrm{C}$ and the absorbance measurements were made again at $30 \mathrm{~min}$ intervals. BHT was used for comparison.

\subsection{Reducing Power Assay}

The reducing power of the extract was based on the method of [22] with slight modification. Extract concentrations of 1, 2, 4, 8 and $16 \mathrm{mg}$ Extract equivalents $/ \mathrm{mL}$ were mixed with potassium ferricyanide (200 $\left.\mathrm{\mu L}, 10 \mathrm{mg} / \mathrm{mL}^{-1}\right)$ and a sodium phosphate buffer (200 $\mu \mathrm{L}, 0.2 \mathrm{M}, \mathrm{pH}$ 6.6) and incubated at $50^{\circ} \mathrm{C}$ for $30 \mathrm{~min}$. Trichloroacetic acid $\left(200 \mu \mathrm{L}, 100 \mathrm{mg} / \mathrm{mL}^{-1}\right)$ was added and the mixtures were again incubated for 5 min to stop 
the reaction. Then, $680 \mu \mathrm{L}$ of the reaction mixtures were mixed with $680 \mu \mathrm{L}$ of distilled water and $68 \mu \mathrm{L}$ of ferric chloride $(10 \mathrm{mg} / \mathrm{mL})$. Absorbance of solution was recorded at $700 \mathrm{~nm}$ Ascorbic acid $(0.5 \mathrm{mM})$ was used standard.

\subsection{Iron-chelating Ability Assay}

The chelating ability of $B$. elegana Choisy seeds extracts for ferrous ions $\mathrm{Fe}^{2+}$ was measured according to the method previously described by [23] with some modifications. To $0.5 \mathrm{~mL}$ of extract in deionized water at different concentrations (1, 2, 4, 8, and $16 \mathrm{mg} / \mathrm{mL}), 1.6$ $\mathrm{mL}$ of deionized water and $0.05 \mathrm{~mL}$ of $\mathrm{FeCl}_{2}(2 \mathrm{mM})$ were added. After $30 \mathrm{~s}, 0.1 \mathrm{~mL}$ ferrozine $(5 \mathrm{mM})$ was added. Ferrozine reacted with the divalent iron to form stable magenta complex species that were very soluble in water. After $10 \mathrm{~min}$ at room temperature, the absorbance of the $\mathrm{Fe}^{2+}-$ Ferrozine complex was measured at $562 \mathrm{~nm}$. The chelating ability of the extract for $\mathrm{Fe}^{2+}$ was calculated using the following equation:

$$
\text { Chelating rate }=\left(\mathrm{A}_{\mathrm{c}}-\mathrm{A}_{\mathrm{s}} / \mathrm{A}_{\mathrm{c}}\right) \times 100
$$

Where:

$A_{c}$ is the absorbance of the control and

$A_{s}$ is the absorbance of extract.

\section{Results}

\subsection{Total Phenol and Flavonoid Contents}

The results showed that the $B$. elegana Choisy seeds ethanolic extract, possessed high phenolic content when measured by Foline-Ciocalteu reagent in terms of gallic acid equivalent $(253.9 \pm 0.9 \mathrm{mg} / \mathrm{g})$ and flavonoid content calculated as catechol equivalent $(23.68 \pm 0.6 \mathrm{mg} / \mathrm{g})$. In the present study, there are good indications that the phenolics of this plant are important components which can have the effect of pharmacological invaluable. It is well known that the flavonoids show antioxidant activity and their effects on human nutrition and health is significant.

\subsection{DPPH Free Radical Scavenging Activity}

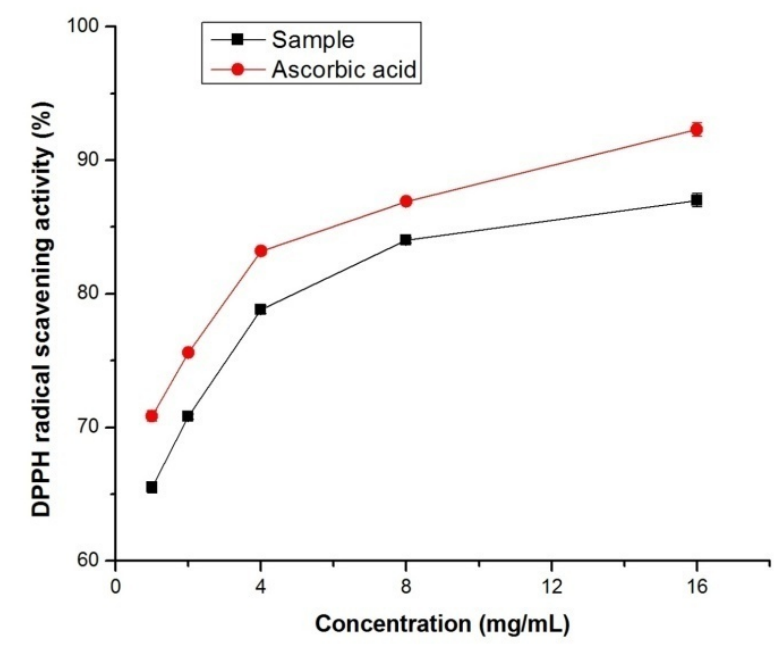

Figure 1. Radical scavenging assay of B. elegana Choisy by DPPH. Values are mean \pm standard deviation of three determinations
DPPH assay is considered one of the most methods which are used widely for screening antioxidant activity of plant extracts. The results of DPPH radical scavenging activity of B. elegana Choisy and the reference antioxidant (Ascorbic acid) are presented in the Figure 1. The seed extract and the reference antioxidant (Ascorbic acid) promoted an inhibition of DPPH radical with increasing concentrations. B. elegana Choisy ethanolic seed extract showed a significant effect in inhibiting DPPH, reaching up to $87.00 \%$ and $92.3 \%$ for the seed extract and standard antioxidant (ascorbic acid), respectively at the highest concentration. $\mathrm{IC}_{50}$ of the sample was (2.42) while control was (1.47). This method is based on scavenging of the $\mathrm{DPPH}$ radical from the antioxidants, which produces a decrease in absorbance at $517 \mathrm{~nm}$.

\subsection{ABTS Radical Scavenging Assay}

The antioxidant activity of B. elegana Choisy was also studied using the ABTS assay. The results of the ethanolic seed extract showed strength and effectiveness in scavenging the ABTS radical as shown in Figure 2, B. elegana Choisy ethanolic seed extract showed a significant effect in inhibiting ABTS, reaching up to $89.3 \%$ and 93.4\% for the seed extract and standard antioxidant (BHT). Respectively at the highest concentration, and this activity was close to that of standard BHT. IC $_{50}$ of the sample was (2.24) while standard was (1.86).

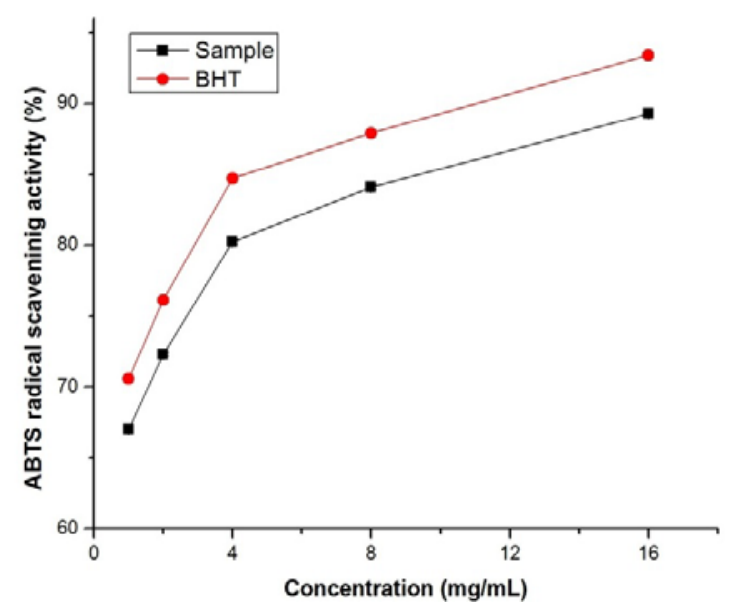

Figure 2. Radical scavenging assay of B. elegana Choisy by ABTS. Values are mean \pm standard deviation of three determinations

\section{4. $\beta$-Carotene Bleaching Test}

The $\beta$-carotene bleaching inhibition effect of the extract of B. elegana Choisy seeds and the standard compound (BHT) are illustrated in Figure 3. The anti-bleaching activity of $\beta$-carotene was estimated by surveillance of color intensity of the emulsion recorded at $470 \mathrm{~nm}$ at every $30 \mathrm{~min}$ for $2 \mathrm{~h}$. The absorbance of both the sample extract and the standard (BHT) at 0 min was $0.245 \mathrm{~nm}$. The concentration of the Extract and the standard (BHT) absorbance of the sample was $0.245 \mathrm{~nm}$. Then, after the next 30 min the sample showed an absorbance of $0.22 \mathrm{~nm}$ bleaching as compared to that of the reference (BHT) at 0.26. After $90 \mathrm{~min}$ of incubation, the absorbance decreased to $0.183 \mathrm{~nm}$ and $0.23 \mathrm{~nm}$ for the sample and the reference (BHT), respectively. Eventually, at the last 120 min, the absorbance was 0.136 and $0.21 \mathrm{~nm}$ for the sample and standard (BHT), respectively. 


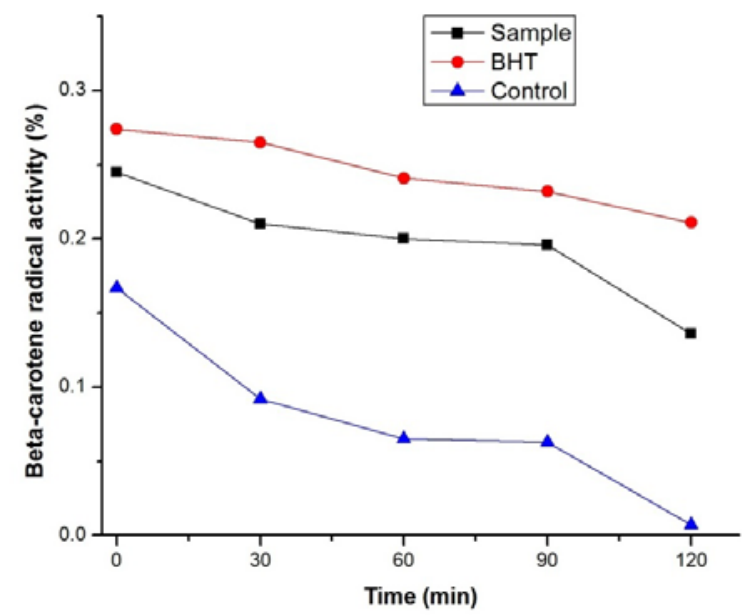

Figure 3. $\beta$-Carotene bleaching activity of B. elegana Choisy. Values are mean \pm standard deviation of three determinations

\subsection{Reducing Power}

The reducing power results of ethanolic extract of $B$. elegana Choisy and reference antioxidant (BHT) are presented in the Figure 4. Both the seeds extract and BHT showed increased absorbance with of increasing concentration.

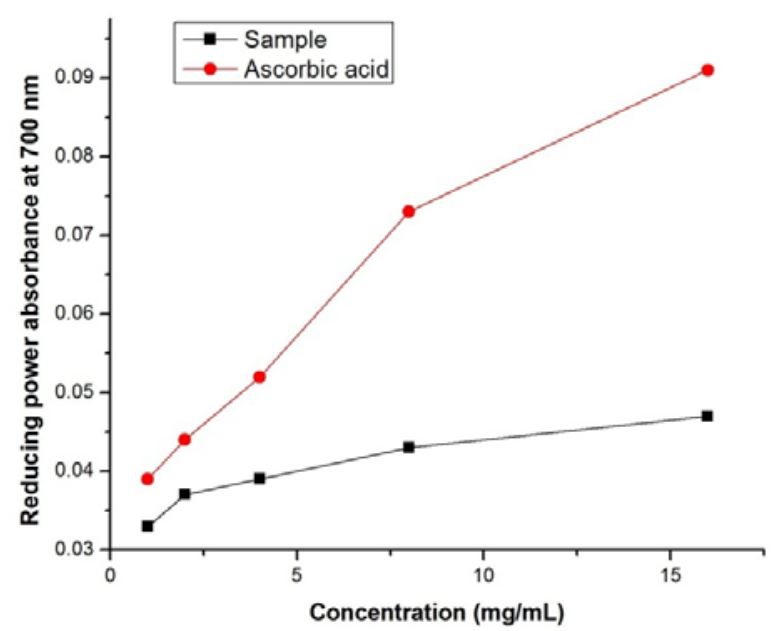

Figure 4. Reducing power of B. elegana Choisy. Values are mean \pm standard deviation of three determinations

\subsection{Iron-chelating Ability}

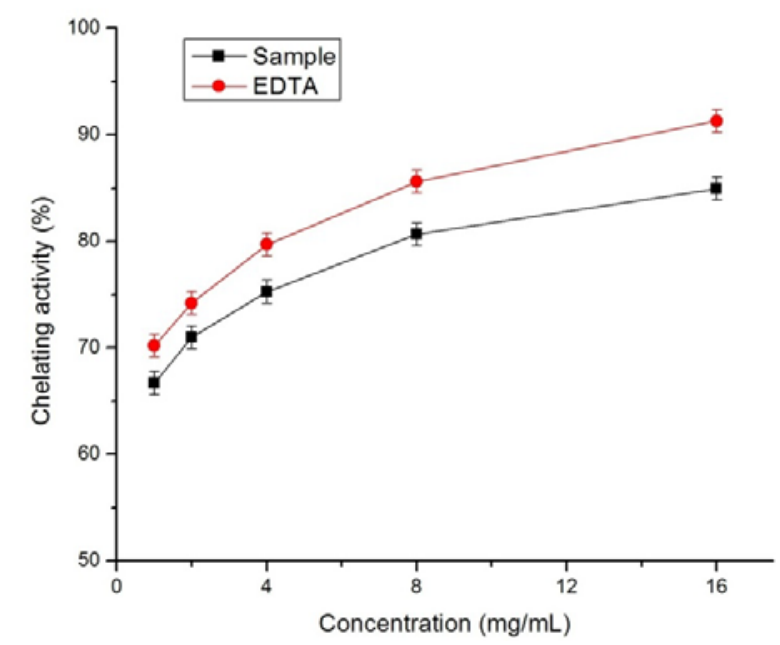

Figure 5. Iron chelating ability of B. elegana Choisy. Values are mean \pm standard deviation of three determinations
Figure 5 presents the iron chelating ability of both $B$. elegana Choisy seeds and reference antioxidant (EDTA), the data obtained of $B$. elegana Choisy extract exhibited potent and increases as the concentration increases, The minimum in vitro chelating ability of the seeds extract was $66.67 \%$ At the lowest concentration and the maximum capacity $84.95 \%$ at the highest concentration, and was seeds extract chelated less iron than efficient than commercial chelator. $\mathrm{IC}_{50}$ of the sample was (6.78) while control was (6.35).

\section{Discussion}

\subsection{Total Phenol and Flavonoid Contents}

Plants are rich sources of natural antioxidants such as phenolics and tocopherols, which are considered to be the best-known components [24]. Phenolic compounds are highly reactive toward free radicals, Hence, quantification of these compounds is also indicative of antioxidant activity [25].It is known that Phenolic compounds from plants are good natural antioxidants. The high phenolic compounds value obtained in B. elegana Choisy seeds is in agreement with the study that analyzed various species of genus Boerhaavia diffusa root [16]. also the value obtained for total phenol content, from this study is higher than the values reported Rocha-Guzmán et al [39] studied total phenol content in three different of common bean. Polyphenolic compounds are antioxidants and may help to prevent diseases associated with oxidative stress, such as atherosclerosis, cancer and neurodegenerative diseases $[26,27,28]$. The value obtained for total flavonoid content from this study was high and this is considered an advantage because of the plants containing phenolic compounds, especially the flavonoids have exhibit strong antioxidant properties [29]. It is also reported by [30,31] that the radical scavenging activity is an indicator of the functionality and antioxidant activity and can be attributed to the contents of total polyphenols and total flavonoids in plant foods.

\subsection{DPPH Free Radical Scavenging Activity}

From Figure 1, B. elegana Choisy demonstrated the capacity for scavenging free radicals by reducing the stable DPPH radical to the yellow colored diphenylpicryl hydrazine. These findings indicated the potential electron and/or hydrogen donating ability of B. elegana Choisy extract. Based on the scavenging capacity of the free radicals, the highest antioxidant activity was found in $B$. elegana Choisy extract. Value of DPPH scavenging activity which found from this study is higher than the values those found by Zhao et al [42] studied the DPPH scavenging activity in 10 kinds of beans. This may be attributed to the presence flavonoids that exhibit strong antioxidant properties [29]. Moreover, [32] reported that antioxidant activity of plant extracts containing polyphenolic compounds have capacity to be donate hydrogen atoms or electrons and to capture the free radicals. However, the radical scavenging potential of the reference antioxidant (Ascorbic acid) was higher than that of the extract.

\subsection{ABTS Radical Scavenging Assay}


The ABTS method depends on the inhibition of the absorbance of radical cation ABTS, which has a feature wavelength at $734 \mathrm{~nm}$. Decolonization of ABTS reflects the capacity of the antioxidant species to donate electrons or hydrogen atoms to inactivate these radical actions. In the presence of antioxidant reductant, the colored radical is converted back to colorless ABTS [33]. The result obtained in this study in ABTS is higher than the values reported by Marathe et al [41] in Common Beans. Also the result of ABTS radical scavenging activities of the extract was comparable to those observed from DPPH assay. ABTS radical scavenging activity is relatively recent, often used for screening complex antioxidant mixtures such as plant extracts, and involves a more drastic radical, chemically produced [15].

\section{4. $\beta$-Carotene Bleaching Test}

In this assay of $\beta$-Carotene bleaching it lost yellow of $\beta$-carotene because of the interaction between $\beta$-carotene with radicals created by linoleic acid oxidation in an emulsion [34]. The result obtained in this study in a $\beta$ carotene is higher than the values reported by CardadorMartínez, et al [40] in some common beans. In the $\beta$ carotene/linoleic acid test has been oxidized the highly unsaturated fatty acids due to the oxidation of linoleic acid which generates peroxyl free radicals. This is an indicator of the presence of antioxidants which minimize the oxidation of $\beta$-carotene compounds.

\subsection{Reducing Power}

In this method the reducing potential of B. elegana Choisy extract was evaluated. The reducing power reflects the electron donating capacity of its bioactive compounds, which serves as a significant indicator of its antioxidant activity. The results exhibited that $B$. elegana Choisy extract, lesser than standard antioxidant, value of reducing power of alhydwan seeds are similar to values of some common legumes, reported by Zhao et al [42] studied the reducing power of 10 kinds of beans. Reduced Fe3+/ferricyanide complex to the ferrous form, which indicated existence of reductants in the sample solution. The presence of these reductants in B. elegana Choisy was considered keys to its reducing power, because they appear as antioxidants by donating a hydrogen atom and breaking the free radical chain [35].

\subsection{Iron-chelating Ability}

The iron-chelating ability assay is considered of importance to screen the iron and mechanism of antioxidant activity and its ability to chelate/deactivate transition metals, it possesses ability to catalyze hydrogen peroxide decomposition and Fenton-type reactions [36]. The value of metal chelating which found in alhydwan seed are close to those found by Carrasco-Castilla et al [12] in from phaseolin and bean protein which were (78\% and $82 \%)$.

It could be attributed the antioxidant activity to the presence of bioactive constituents [37]. Such as total polyphenols, total flavonoids, radical scavenging activity, antioxidant capacity and Fe-chelating activity [25]. Furthermore, phenolic compounds are responsible of Fe chelating activity and a high correlation exists between
Fe-chelating ability with flavonoids and phenolic compounds exhibited redox properties (i.e. serves as reducing agents, hydrogen donators and singlet oxygen quenchers) [38,30,31].

\section{Conclusion}

The findings of this study have clearly demonstrated the interesting antioxidant properties of Boerhavia elegana Choisy seeds. The seeds extract exhibited potent the most promising free radical scavenging effects evaluated by DPPH and ABTS tests and a good antioxidant activity through different mechanisms of action (FRAP assay, bcarotene bleaching test, $\mathrm{Fe}^{2+}$ chelating assay). The seeds extract was characterized by the high content of phenols and flavonoids signifying potent antioxidant properties. Eventually, the results showed that Boerhavia elegana Choisy seeds may be used as a source of healthy compounds for the development of dietary supplements and to protect against oxidative stress besides used for food consumption.

\section{Acknowledgement}

We gratefully acknowledge Professor Hui Zhang and our colleagues for the excellent guidance and technical assistance during this work.

\section{References}

[1] Siger A., Czubinski J., Kachlicki P., Dwiecki K., LampartSzczapa E., and Nogala-Kalucka M., Antioxidant "Antioxidant activity and phenolic content in three lupin species." Journal of Food Composition and Analysis, 25. 190-197. 2012.

[2] Al-Farsi., Mohamed Ali., and Chang Yong Lee., "Optimization of phenolics and dietary fiber extraction from date seeds." Food Chemistry 108, 977-985, 2008.

[3] Majhenič L., Mojca Š., and Željko K., "Antioxidant and antimicrobial activity of guarana seed extracts." Food chemistry, 104. 1258-1268. 2007.

[4] Subhasree B., Baskar R., Laxmi Keerthana R., Lijina Susan R., and Rajasekaran P., "Evaluation of antioxidant potential in selected green leafy vegetables." Food chemistry, 115. 1213-1220. 2009.

[5] Osawa T., Kavakishi S., Namiki M., Kuroda Y., Shankal, D M., and Waters M D "Antimutagenesis and anticarcinogenesis mechanisms II." New York: Plenum; 139-153. 1990.

[6] Pandey K B., and Syed I R., "Plant polyphenols as dietary antioxidants in human health and disease." Oxidative Medicine and Cellular Longevity, 2. 270-278. 2009.

[7] Thitilertdecha N., Teerawutgulrag A., and Rakariyatham N., "Antioxidant and antibacterial activities of Nephelium lappaceum L. extracts." LWT-Food Science and Technology, 41. 2029-2035. 2008.

[8] Chanwitheesuk A., Teerawutgulrag A., and Rakariyatham N., "Screening of antioxidant activity and antioxidant compounds of some edible plants of Thailand." Food chemistry, 92. 491-497. 2005.

[9] Rezaire A., Robinson JC., Bereau D., Verbaere A., Sommerer N., Khan M. K., and Fils-Lycaon B., "Amazonian palm Oenocarpus bataua ("patawa"): Chemical and biological antioxidant activityPhytochemical composition." Food chemistry, 149. 62-70. 2014.

[10] Duenas M., Hernandez T., EstrellaI., and Fernandez D., "Germination as a process to increase the polyphenol content and antioxidant activity of lupin seeds (Lupinus angustifolius L.)." Food chemistry, 117. 599-607. 2009.

[11] Beninger Clifford W., and George L Hosfield., "Antioxidant flavonoids from Phaseolus vulgaris L. seed coat color genotypes." Journal of agricultural and Food chemistry 51: 7879-7883.2003. 
[12] Carrasco-Castilla J., Hernández-Álvarez A J., Jiménez-Martínez C., Jacinto-Hernández C., Alaiz M., Girón-Calle J.,and DávilaOrtiz G.,. "Antioxidant and metal chelating activities of peptide fractions from phaseolin and bean protein hydrolysates." Food chemistry 135: 1789-1795. 2012.

[13] Boulos, Loutfy. "contribution to the flora of South Yemen (PDRY)." Candollea, 43.549-585. 1988.

[14] Olaleye M T., Akinmoladun A C., Ogunboye A A., and Akindahunsi A A., "Antioxidant activity and hepatoprotective property of leaf extracts of Boerhaavia diffusa Linn against acetaminophen-induced liver damage in rats." Food and Chemical Toxicology, 48. 2200-2205. 2010.

[15] Govindan P., and Suriyavathana M., "Evaluation of total phenolic content and free radical scavenging activity of Boerhavia erecta." Journal of Acute Medicine, 3. 103-109. 2013.

[16] Khalid M., Hefazat Hussain S., and Sheeba F., "In vitro estimation of the antioxidant activity and phytochemical screening of Boerhaavia diffusa root extract." Asian Journal of Traditional Medicines, 6. 2011.

[17] Wu SJ., Ng LT., "Antioxidant and free radical scavenging activities of wild bitter melon (Momordica charantia Linn. Var. abbreviate Ser.) In Taiwan." LWT-Food Science and Technology, 41. 323-330. 2008.

[18] Djeridane A., Yousfi M., Nadjemi B., Boutassaouna D., Stocher P., Vidal N., "Antioxidant activity of some Algerian medicinal plants extracts containing phenolic compounds." Food Chemistry, 97.654-660. 2006.

[19] Brand-Williams W., Culvelier ME., and Berset C., "Use of a free radical method to evaluate antioxidant activity,” LebensmittelWissenschaft \& Technologie, 28. 25-30.1995.

[20] Azhari S., Y S Xu., Q X Jiang., and W S Xia., "Physicochemical properties and chemical composition of Seinat (Cucumis melo var. tibish) seed oil and its antioxidant activity." Grasas y Aceites, 65.2014.

[21] Lu Y., Yeap Foo L., "Antioxidant and radical scavenging activities of polyphenols from apple pomace." Food chemistry, 68.81-85. 2000.

[22] Zheng L., Huang X., Wang L., Chen Z., "Physicochemical properties, chemical composition and antioxidant activity of Dalbergia odorifera T. Chen seed oil." Journal of the American Oil Chemists' Society, 89. 883-890.2012.

[23] Dinis T C., Madeira V M., Almeida L M., "Action of phenolic derivatives (acetaminophen, salicylate, and 5-aminosalicylate) as inhibitors of membrane lipid peroxidation and as peroxyl radical scavengers."Archives of biochemistry and biophysics, 315. 161169.1994.

[24] Jiao J., Li Z G., Gai Q Y., Li X J., Wei FY., Fu Y J., and Wei M. "Microwave-assisted aqueous enzymatic extraction of oil from pumpkin seeds and evaluation of its physicochemical properties, fatty acid compositions and antioxidant activities." Food chemistry, 147. 17-24.2014

[25] Loizzo M R., Tundis R., Bonesi M., Menichini F., Mastellone V., Avallone L., Menichini F., "Radical scavenging, antioxidant and metal chelating activities of Annona cherimola Mill.(cherimoya) peel and pulp in relation to their total phenolic and total flavonoid contents." Journal of Food Composition and Analysis, 25. 179-184. 2012.

[26] Steinmetz K A., and Potter J D., "Vegetables, fruit, and cancer prevention: a review." Journal of the American Dietetic Association, 96, 1027-1039.1996.
[27] La Vecchia C., Altieri A., and Tavani A., "Vegetables, fruit, antioxidants and cancer: a review of Italian studies." European Journal of Nutrition, 40. 261-267.2001.

[28] Zibadi S., Farid R., Moriguchi S., Lu Y., Foo L Y., TehraniP M., Judith B U., and Watson R R., "Oral administration of purple passion fruit peel extract attenuates blood pressure in female spontaneously hypertensive rats and humans." Nutrition research, 27. 408-416. 2007.

[29] Raj K J., and Shalini K., "Flavonoids-a review of biological activities." Indian Drugs, 36, 668-676.1999.

[30] Heim K E., Tagliaferro A R., and Bobilya D J., "Flavonoid antioxidants: chemistry, metabolism and structure-activity relationships." The Journal of nutritional biochemistry, 13, 572584.2002.

[31] Balasundram N., Kalyana., and Samir S., "Phenolic compounds in plants and agri-industrial by-products: Antioxidant activity, occurrence, and potential uses." Food chemistry, 99. 191-203.2006.

[32] Sahoo S., Ghosh G., Das D., and Nayak S., "Phytochemical investigation and In vitro antioxidant activity of an indigenous medicinal plant Alpinia nigra BL Burtt." Asian Pacific journal of tropical biomedicine, 3, 871-876. 2013.

[33] Sreejayan N., and Rao M N., "Free radical scavenging activity of curcuminoids." Arzneimittel-forschung, 46, 169-171. 1996.

[34] Nanasombat S., and Wimuttigosol P., "Antimicrobial and antioxidant activity of spice essential oils." Food Science and Biotechnology, 20. 45-53.2011.

[35] Thenmozhi A., Nagalakshmi K., and Rao U Ma., "Qualitative analysis of phytochemicals, and comparative superoxide radical scavenging along with reducing potency of Solanum nigrum using various solvent extracts."International Journal of Green Pharmacy, 5. 318-324. 2011

[36] Nair VD., Panneerselvam R., and Gopi R., "Studies on methanolic extract of Rauvolfia species from Southern Western Ghats of IndiaeIn vitro antioxidant properties, characterization of nutrients and phytochemicals". Industry Crops Production, 39, 17-25. 2012.

[37] Barreira J., Ferreira IC., Oliveira MB P P., and Pereira JA., "Antioxidant activity and bioactive compounds of ten Portuguese regional and commercial almond cultivars." Food and chemical toxicology, 46. 2230-2235. 2008.

[38] Soong YY., and Philip J B., "Antioxidant activity and phenolic content of selected fruit seeds." Food Chemistry, 88, 411417.2004.

[39] Rocha-Guzmán N E.,Herzog A., González-Laredo R F., IbarraPérez, F J., Zambrano-Galván G., and Gallegos-Infante J A., "Antioxidant and antimutagenic activity of phenolic compounds in three different colour groups of common bean cultivars (Phaseolus vulgaris)." Food chemistry 103; 521-527, 2007.

[40] Cardador-Martínez, Anaberta, Guadalupe Loarca-Piña, and B. Dave Oomah., "Antioxidant Activity in Common Beans (Phaseolus vulgaris L.) §." Journal of Agricultural and Food Chemistry 50. 6975-6980, 2002.

[41] Marathe S A., Rajalakshmi V., Jamdar S N., and Sharma, A., "Comparative study on antioxidant activity of different varieties of commonly consumed legumes in India." Food and Chemical Toxicology 49: 2005-2012.2011.

[42] Zhao Y., Du S K., Wang H., and Cai M. "In vitro antioxidant activity of extracts from common legumes." Food chemistry 152: 462-466, 2014. 